\title{
Nitrofurantoin Sodium
}

National Cancer Institute

\section{Source}

National Cancer Institute. Nitrofurantoin Sodium. NCI Thesaurus. Code C66241.

A sodium salt form of nitrofurantoin, a synthetic derivative of imidazolidinedione (hydantoin) that inhibits bacterial DNA, RNA, and cell wall protein synthesis. 